\title{
A modernização do material e do pessoal da Marinha nas vésperas da revolta dos marujos de 1910: modelos e contradições
}

\section{The modernization of the staff and war materiel in the Brazilian navy on the eve of the sailors' mutiny in 1910: models and contradictions}

Silvia Capanema P. Almeida

Modernidade é uma noção complexa. Antes de tudo, diz respeito a um contexto no qual se inserem atores - convictos de que estão imersos em um processo de mudanças - e sobre o qual pensam intelectuais e historiadores - que a definem como um período de longa duração em que se esboça com maior clareza o conceito de sujeitos de ação (Arendt, 1982; Dumond, 1983; Le Goff, 1988). Mas a modernidade pode ser também um discurso utilizado para justificar me-

Silvia Capanema P. Almeida é pesquisadora do Centro de Pesquisas MASCIPO (Mondes Américains, Sociétés, Circulations et Pouvoirs) da École des Hautes Études en Sciences Sociales - EHESS, Paris, França (silvia.capanema@gmail.com).

Artigo recebido em 30 de dezembro de 2009 e aprovado para publicação em 8 de abril de 2010.

Est. Hist., Rio de Faneiro, vol. 23, $n^{o}$ 45, p. 147-169, janeiro-junho de 2010. 
didas sempre tomadas em nome da necessidade de "modernização". Assim, ela não possui existência concreta, é exclusivamente imaginada.

O ponto de partida deste artigo é demonstrar em que medida o início da República brasileira constituiu, para instituições oficiais como a Marinha de Guerra, um novo momento de afirmação dos ideais da modernidade, depois da Independência e do Império, contornado pelas noções de progresso, civilização e ordem, mesmo que isso não implique dizer que existia um único e coeso projeto de modernização nem que os resultados pretendidos tenham sido alcançados. Ao contrário, observa-se na Marinha, como em outras instâncias, continuidades e descontinuidades, bem como diferentes visões, e os ideais republicanos de modernidade, muitas vezes, somente existiam em discursos e modelos. Meu objetivo final é discutir um paradigma tradicional da Primeira República, segundo o qual o período e o universo em questão se caracterizariam por um importante abismo entre a dimensão material - supervalorizada - e pessoal - menosprezada.

Segundo alguns historiadores navais, o progresso técnico do início do século tinha como consequência imediata a substituição do pessoal da Armada. Assim, o trabalho a bordo na época dos navios a vela exigia verdadeiros "homens feras", recrutados tradicionalmente pela polícia e "adestrados" por uma disciplina rigorosa, que compreendia diferentes formas de castigos corporais (Martins, 1988). De acordo com uma expressão utilizada pelo vice-almirante Hélio Leôncio Martins (1988:87), os marujos do tempo do barco a vela eram "homens de ferro em navios de madeira". Porém, no início do século XX, esses navios - "jaulas flutuantes" - foram substituídos pelos encouraçados, que exigiam um novo tipo de pessoal, mais bem formado e avesso às antigas medidas disciplinares. Segundo essa corrente, o erro da Marinha brasileira do início do século que levou à revolta dos marujos em 1910 contra os castigos corporais ${ }^{1}$ foi o de tentar substituir os navios de guerra sem proceder à troca do pessoal de bordo, criando um abismo entre essas duas dimensões.

A discrepância entre as esferas dos equipamentos e humana nesse contexto remonta à argumentação de Gilberto Freyre, ainda que para denunciar as más condições de vida dos marinheiros. Em Ordem e Progresso, o conhecido sociólogo sustenta que a República brasileira teria falhado, sobretudo durante os governos de Rodrigues Alves (1902-1906) e Afonso Pena (1906-1909), pois "cuidou-se da modernização das coisas e das técnicas sem se cuidar ao mesmo tempo da adaptação dos homens e das pessoas a novas situações criadas pela ampliação ou pela modernização tecnológica da vida brasileira" (2000:899). Freyre se apoia nos argumentos apresentados pelo oficial José Eduardo Macedo Soares, em uma obra publicada clandestinamente em 1911, na qual tenta explicar "os tristes acontecimentos de 1910" a partir dos problemas internos da Marinha e da Repú- 
blica brasileira. De acordo com esse outro autor, que assina seu livro como "um oficial da Marinha":

O erro inicial esteve na superposição do problema do material sobre o problema do pessoal. Caso os governos tivessem nas épocas de penúria renovado o quadro dos oficiais (...), modificado a situação da marinhagem, isolando os marinheiros provenientes das escolas da massa incorrigível que deveria ser eliminada, nós teríamos podido em tempo próprio realizar o programa naval. (...) A primeira impressão que produz uma guarnição brasileira é de decadência e incapacidade física. Os negros são raquíticos, mal encarados, com todos os signos deprimentes das mais atrasadas nações africanas. As outras raças submetem-se à influência de meio criada pelos negros sempre em maioria. Profundamente alheios a qualquer noção de conforto, os nossos marinheiros vestem-se mal, não sabem comer, não sabem dormir. Imprevidentes e preguiçosos, eles trazem da raça a tara da incapacidade de progredir. (Macedo Soares, 1911:84-86).

Ora, é justamente a partir desse estudo, marcado pelas teorias raciais da época em questão, que tem origem o paradigma da contradição do pessoal e do material na modernização da Marinha de guerra, tão utilizado por diversos pesquisadores civis ou militares, mesmo se propondo argumentos bem distintos. ${ }^{2}$ No entanto, uma pesquisa a partir dos relatórios dos ministros da Marinha $(\mathrm{RMM}),{ }^{3}$ de obras da época, da correspondência diplomática ou militar e dos arquivos das escolas de aprendizes-marinheiros permite relativizar essas abordagens. Com efeito, no quadro da Marinha brasileira da Primeira República, a modernização implantada abrange tanto uma reforma dos equipamentos quanto uma proposta de resolução para o problema do recrutamento e formação de praças, através de "soluções" pensadas especialmente durante a gestão de Alexandrino de Alencar (1906-1910).

Afirmar isso não significa dizer que esses projetos fossem uniformes e isentos de críticas e limitações e que não houvesse, em sua concretização, a manifestação de preconceitos e de interesses pessoais. Ao contrário, o que se pretende demonstrar é que havia, no contexto estudado, projetos modernizadores que envolviam as duas dimensões - humana e material - mas que essas iniciativas eram repletas de contradições internas, mas não correspondiam necessariamente a uma contradição que opusesse essas duas dimensões entre si. Como veremos, não se pode dizer que os projetos de reaparelhamento da Marinha eram fabulosos e perfeitos, nem que não houvesse um investimento de ideias e de fundos 
para resolver a questão humana. Assim, esse novo olhar possibilita pensar de que maneira os praças da Marinha também se incluíam nesse projeto mais amplo de modernização.

\section{A modernização técnica}

A consolidação da Marinha brasileira remonta ao período imperial. A Armada teve um papel decisivo na repressão ao tráfico negreiro a partir de $1850 \mathrm{e}$ na Guerra do Paraguai (1864-1870), que acelerou a substituição progressiva das embarcações. Num intervalo de pouco mais de 20 anos, entre 1848 e 1870, quase a totalidade dos navios a vela cederam lugar aos vapores, que permitiam a adoção do sistema misto vela-vapor e aos encouraçados (Arias Neto, 2001:80). Em seu potencial, tanto de ruptura quanto de continuidade, a chegada da República introduziu mudanças relativas ao lugar que o Brasil pretendia ocupar no cenário internacional. Desde o início do novo regime, os diferentes ministros tornaram públicas suas reclamações em seus relatórios anuais e a revolta dos oficiais de 1893 pode ser compreendida, nesse contexto, como um marco. Ela expressa o extremo da insatisfação dos oficiais da Marinha e também pode ser vista como um auge no desmonte de forças humanas e materiais.

Todavia, o final do século inaugura uma retomada dos investimentos na Armada brasileira. Dotar a República de uma Marinha poderosa, que garantisse visibilidade ao país e a presença de sua bandeira no exterior, além de um lugar hegemônico na América do Sul e a defesa do território nacional, torna-se uma necessidade primordial, sobretudo durante o período em que Rio Branco ocupa o Ministério das Relações Exteriores entre 1902 e 1912 (Bueno, 2003). A experiência das guerras sino-japonesa de 1894-1895 e russo-japonesa de 1904-1905 colocava ainda mais em evidência essa necessidade para os combates "modernos", que mostravam a importância da logística e da colaboração entre tropas terrestres e navais e a necessidade do poder bélico na defesa. É nesse contexto que surge a ideia de elaborar um verdadeiro projeto naval para o Brasil, fato inédito até então.

No entanto, se havia um certo consenso sobre a necessidade desse projeto naval, a forma como ele deveria ser orientado não era uma unanimidade e os recursos financeiros nem sempre podiam ser assegurados. Nos outros países do mundo, havia pelo menos duas formas de pensar a construção bélica naval. $\mathrm{Na}$ França, a chamada Feune Ecole defendia, a partir da segunda metade do século XIX, a aquisição de embarcações pequenas, ligeiras e menos custosas, como torpedeiros e cruzadores, em detrimento dos grandes encouraçados (Verge-Franceschi, 2002: 801-802). Já nos Estados Unidos, o modelo, sintetizado nos estudos 
do almirante Mahan, sustentava que o combate moderno deveria acontecer em alto-mar, com o uso dos grandes navios (Verge-Franceschi, 2002: 900). A estratégia da feune Ecole era mais defensiva que ofensiva, sendo acusada, anos mais tarde, como responsável pelo atraso da Marinha francesa após a Primeira Guerra, enquanto o modelo pensado por Mahan era também tido como insuficiente, por menosprezar a importância crescente dos submarinos.

O Brasil procurava se situar nesse debate e acompanhar a corrida armamentista dos países vistos como "mais avançados". Enquanto o pretendido "projeto naval" mal começava a ser discutido no Congresso e nos meios militares, as encomendas feitas a partir de 1896 se destinavam, em sua maior parte, aos grandes construtores europeus, como o grupo inglês Amstrong, os franceses Forges et Chantiers e a sociedade polonesa Vulcain. Somente dois novos navios seriam construídos na capital federal (RMM, 1896: 101). A modernização naval brasileira marcava, assim, a reafirmação da posição do Brasil no ciclo de dependência bélico, alvo das disputas entre os países construtores de armamentos. Porém, o relatório do ministro de 1897 indica também que o país encontrava dificuldade em honrar o pagamento das encomendas feitas na Europa e que a Marinha via-se obrigada a anular uma parte dos pedidos, a vender alguns navios já terminados e a cancelar as construções planejadas para o Brasil, por falta de meios para pagar o pessoal.

O Brasil não era o único país sul-americano que se envolvia nas questões armamentistas. O embaixador brasileiro em Buenos Aires relatou ao ministro das Relações Exteriores sobre o considerável desenvolvimento da Marinha argentina, que tinha passado de 6.114 toneladas em 1875 a 94.891 em 1900. A Argentina gozava, portanto, da superioridade bélica e o Brasil deveria recuperar, de qualquer maneira, o lugar de primeira potência naval no subcontinente (Bueno, 2002: 288-232). Nesse contexto, um primeiro projeto foi enfim apresentado pelo ministro Júlio César de Noronha, correspondendo à sede de modernização que marcava a presidência de Rodrigues Alves. O "projeto de 1904" caracterizava-se pela proposta de compra de navios menores e de custo mais baixo, como encouraçados médios, torpedeiros e contra-torpedeiros, que tinham mostrado sua eficiência na batalha de Porto-Artur, uma das mais sangrentas da guerra russo-japonesa. Segundo suas próprias palavras:

Eis, pois, em resumo, o meu programa a realizar-se no decurso de seis a oito anos: 3 couraçados de 12.500 a 13.000 tons de deslocamento; 3 cruzadores couraçados de 9.200 a 9.700 tons.; 6 caça-torpedeiros de 400 tons.; 6 torpedeiras de 130 tons.; 6 torpedeiras de 50 tons; 3 submarinos; 1 vapor carvoeiro, capaz de carregar 6.000 tons de combustível. (RMM, 1903:11). 
Pela primeira vez, o Brasil pretendia desenvolver um projeto naval integrado, já que as encomendas anteriores tratavam somente da aquisição de peças individuais e não de um conjunto (Martins Filho, 2010). No último relatório assinado por Noronha - relativo a 1905 -, o ministro faz saber que, após uma concorrência entre diversas construtoras estrangeiras, a companhia inglesa Armstrong Whitworth \& Co. Limited se encarregaria da construção dos três encouraçados "por ser, dentre as que satisfizeram todos os requisitos exigidos, a de menor preço" (RMM, 1905: 5). Porém, estudos mostram que a firma inglesa teria contado também com a existência de interesses privados e a boa política de seus agentes, já que a encomenda "jamais teria sido conseguida não fossem os enormes pots-de-vin generosamente distribuídos às mais altas autoridades navais e outras personagens envolvidas", como atesta a correspondência do Foreign Office britânico, citada por José Roberto Martins Filho (2010).

Pouco depois da aprovação unânime do projeto pelo Congresso brasileiro e de sua transformação em lei em dezembro de 1904, as críticas e as propostas de modificação já apareciam. Elas voltavam-se contra as pequenas dimensões dos navios de guerra, sobretudo depois do lançamento aos mares do moderníssimo encouraçado inglês modelo dreadnought em 1906, cuja construção havia sido inciada em outubro de 1905. Mas as mudanças efetivas só entraram em vigor um pouco mais tarde. Nesse mesmo ano, o ministro Noronha tentou defender o seu projeto, argumentando em seu relatório:

A guerra russo-japonesa, pondo em relevo a utilidade de uma Marinha poderosa, levou as principais potências marítimas à construção de navios de grande deslocamento. E como cada uma quer a primazia no domínio do mar, construído o Dreadnought, de 18.000 toneladas, o Japão, a Alemanha, e a França, cujos orçamentos comportam largas despesas, imitaram a Grã-Bretanha. Esse deslocamento (...) será avolumado dentro em pouco. (...) E o Brasil, que em assunto de Marinha tem muito a fazer, que é tributário do estrangeiro e nem sequer dispõe de um arsenal aparelhado para a conservação dos navios projetados, poderá seguir a perigosa trilha ora encetada pelas nações de primeira ordem? (RMM, 1905:7).

Noronha é substituído em 1906 por Alexandrino de Alencar. Originário do Rio Grande do Sul e filho de oficial da Marinha, ele havia combatido na guerra do Paraguai e participado da revolta de 1893. Anistiado, viria a ocupar a pasta da Marinha entre 1906 e 1910, 1913 e 1918, 1922 e 1926, sendo reconhecido, no interior da Armada brasileira, como um de seus heróis (Alencar, 1989). Como o projeto de Noronha não tinha saído do papel, reúnem-se as condições para alterá-lo e os 
construtores ingleses aceitam a proposta de modificar as encomendas. $\mathrm{O}$ debate dividiu o Congresso entre aqueles favoráveis à construção de navios mais modestos e os defensores da aquisição de dreadnoughts. O ministro Alexandrino representava esta segunda corrente. Decidiu-se que um novo projeto seria elaborado, respeitando-se, contudo, os créditos concedidos ao projeto de Noronha.

O novo decreto, promulgado em novembro de 1906, não estabelecia a velocidade e as características das embarcações, provavelmente por medo de que se tornassem obsoletas, como acontecera com a proposta de Noronha. A decisão final ficou conhecida como parte integrante do projeto "Rumo ao mar" do almirante Alexandrino e, em 1907, foi dada ordem para a construção dos dreadnoughts Minas Gerais e São Paulo, de mais de 18.000 toneladas de deslocamento. O governo desistiu do encouraçado Rio de Faneiro, que, vendido à Turquia, participou dos combates da Primeira Guerra. A historiografia aponta duas razões para a anulação da compra deste terceiro navio: os altos custos das encomendas e a pressão de outras nações sul-americanas, nomeadamente da Argentina. De fato, tanto a imprensa argentina quanto os diplomatas do país denunciavam as pretensões armamentistas brasileiras, acusando a diplomacia de Rio Branco de "expansionista" e "imperialista", embora o ministro não defendesse particularmente o projeto de Alexandrino e fosse mais favorável à compra de navios menores, nos moldes do projeto de Noronha (Heinsfeld, 2006; Bueno, 2003:223). De toda forma, as novas aquisições brasileiras embarcarão o país vizinho em uma verdadeira corrida armamentista e, no início de 1910, a Argentina encomenda dois dreadnoughts de 28.000 toneladas de deslocamento.

As nações europeias também assistirão com desconfiança a essa sede de renovação dos equipamentos navais brasileiros, buscando ainda enquadrar seus próprios interesses. Uma nota do representante francês em função no Brasil em 1908 se interroga a propósito das encomendas da Marinha brasileira: "A que objetivo imediato respondem esses armamentos? Tratar-se-ia de um acesso, custoso aliás, de megalomania? Ou será que o Brasil teme realmente um conflito com a República Argentina com relação à jurisdição das águas do Rio de la Plata?"4

Do lado europeu, era preciso tentar garantir uma parte, fosse ela pequena, desse "bolo". Os diplomatas franceses, por exemplo, estudavam responder às demandas da Marinha brasileira e, mesmo quando não podiam concorrer diretamente, faziam uso de outros métodos para assegurar pequenas vantagens, como atesta a carta do representante desse país em Petrópolis em maio de 1909, endereçada ao ministro de Relações Exteriores francês:

O governo brasileiro acaba de encarregar a indústria francesa dos consertos do navio-escola Benjamin Constant. Os trabalhos 
a serem feitos se elevam a aproximadamente 1.500 .000 francos. M. Lambert, negociante francês residente no Rio de Janeiro há muitos anos e que está em contato com o ministro da Marinha, tinha me pedido para intervir a seu favor junto ao almirante Alencar para convencê-lo a confiar à Forges et Chantiers do Mediterrâneo as reparações desse navio de guerra, construído, aliás, por essa companhia metalúrgica francesa. Construtores ingleses tinham apresentado ofertas sensivelmente mais vantajosas e nos ameaçavam. As conversas que tive com o ministro da Marinha convenceram-no a nos dar preferência. ${ }^{5}$ (grifo nosso)

Além disso, da mesma forma que o projeto brasileiro alimentava as rivalidades com os vizinhos do subcontinente, através dele também eram recolocados problemas relativos às inimizades existentes entre os países europeus, como nos revela este outro extrato da correspondência diplomática francesa, a respeito do envio de um adido naval ao Brasil:

A Alemanha, é verdade, se contenta por enquanto com um simples oficial anexo à sua legação, mas a Inglaterra, os Estados Unidos e a Argentina têm adidos navais ou militares, conforme o caso. Esse ato de cortesia só poderia agradar aos brasileiros. Como podemos prever, sem medo de errar, que cedo ou tarde, ele será executado pela Alemanha, melhor seria, a meu ver, precedê-la do que sucedê-la. ${ }^{6}$

No final das contas, o programa "Rumo ao Mar" reduziu-se à compra de dois dreadnoughts, dois scouts e dez destroyers, entregues ao Brasil a partir de 1908. Se as construções destinavam-se na maior parte às companhias inglesas, na incorporação dos navios inventava-se uma forma de fazer bem brasileira, ou copiava-se uma tradição dos Estados Unidos. A partir de então, os principais navios da frota serão batizados com os nomes dos estados da República federalista, como Minas Gerais, São Paulo, Bahia, Rio Grande do Sul, assim como no vizinho do Norte existem os USS Texas, USS Michigan, USS South-Carolina.

Para além das críticas e dos jogos de interesses diplomáticos, a chegada dos navios foi recebida com grande elã popular. Em abril de 1910, ela foi narrada com ufanismo por O Paiz :

A chegada do Minas Gerais, eis o grande acontecimento que ontem fez palpitar numa vibrante emoção patriótica toda a alma nacional (...) Os brasileiros (...) saudavam no vulto de aço do Minas Gerais o Brasil novo, opulento e poderoso, que vai na sua rota de progresso e civi- 
lização com a mesma galhardia com que o primeiro de seus dreadnoughts - o primeiro dreadnought do mundo - entrou nas águas espelhantes da Guanabara. (O Paiz, 18/04/1910).

O palhaço e compositor popular negro, Dudu das Neves, dedicou ao encouraçado gigante uma de suas mais populares canções. Hoje reconhecida como hino do estado de Minas Gerais, a letra original, escrita para a melodia italiana Vienne sul mare, dizia:

Louros triunfais/ O século nos traz/Vamos saudar o gigante do mar/ Oh, Minas Gerais!/ Viva a armada, viril, brasileira/ Que hoje pode, orgulhosa, cantar/É no mar, pelo sul, a primeira/ Pois ostenta o gigante do mar/ Já não teme os poderes navais/ E, também, poderosa $\mathrm{e}$ viril/ Basta a força do Minas Gerais/ Pra defesa do nosso Brasil!

Esse tom ufanista - também presente, no mesmo período, com relação à modernização do recrutamento naval, como veremos a seguir - terá seus limites e suas contradições. Junto com os navios, mudavam-se também as relações de trabalho e, a bordo de cada um deles, conviviam a serviço entre 500 e 1.000 homens, outro fato novo na Marinha brasileira. Quanto ao "poder" dos gigantes dreadnoughts brasileiros, o Minas e o São Paulo serão rapidamente ultrapassados pelos inventos da corrida armamentista provocada pela Primeira Guerra Mundial. E o Brasil não reunirá as condições necessárias para acompanhar essa concorrência.

\section{A modernização do pessoal}

Os problemas do recrutamento militar no século XIX na Marinha como no Exército, no Brasil e nos outros países da América Latina, já foram demonstrados pela historiografia (Beattie, 2001; Castro, Izecksohn, Kraay, 2004). O baixo número de voluntários devia ser equilibrado pelo recrutamento forçado, cujo resultado era a mesma origem social dos praças: excluídos, indigentes, homens livres pobres e escravos enviados, frequentemente, como substitutos de seus proprietários. A polícia também podia contribuir para o preenchimento dos claros das Forças Armadas, enviando condenados e capturando à força homens pobres e marinheiros a serviço da Marinha mercante. Porém, essas práticas não podem conduzir o historiador unicamente a generalizações. É preciso estar atento também para a existência de casos em que a carreira de praça de Marinha e do Exército podia ser uma alternativa, sobretudo para escravos, livres e libertos (Almeida, 2009). 
O altíssimo número de deserções complicava o quadro de constantes subefetivos (Almeida, 2009:92). O problema da falta de braços era repetidamente apresentado pelos ministros da Marinha em seus relatórios e se explicava, segundo o ministro Eduardo Wandenkolk, pela verdadeira "repugnância que em geral manifesta a nossa população para a vida marítima militar" (RMM, 1890:13). Duas soluções para a falta de pessoal foram pensadas ainda durante o Império. Em 1840, foi criada a Companhia de Aprendizes Marinheiros para fornecer marujos para a Armada Nacional. Os principais argumentos utilizados para a sua fundação eram a garantia de braços e a importância da formação técnica, mas também primária, indispensável ao bom marinheiro. Nas Companhias de Aprendizes deveriam se inscrever menores entre dez e 17 anos, idade em que se tornavam grumetes, levados pelos pais ou tutores que deveriam receber uma gratificação pelo alistamento das crianças. Estes eram os termos da lei, mas, como sabemos, muitas vezes a prática da Marinha diferia bastante do previsto no papel. As companhias também podiam ser alimentadas pela inscrição de órfãos, crianças abandonadas e pequenos delinquentes, enviados pelas autoridades policiais e judiciárias.

Outra alternativa pensada foi o sorteio marítimo militar, transformado em lei em 1874. O decreto excluía diversos estratos da população, como os fisicamente inaptos, os diplomados e os trabalhadores de alguns setores, como os ferroviários, a fim de preservar o mercado de trabalho da época. Contudo, o sorteio não foi posto em prática imediatamente e, quando finalmente executado, em 1903, revelou-se um verdadeiro fracasso. Estabelecido que os empregados do setor marítimo seriam o público alvo, já que tinham o conhecimento necessário para o trabalho a bordo dos vasos de guerra, os trabalhadores portuários organizaram uma greve alguns dias antes do sorteio e muitos dos sorteados apresentaram atestados médicos ou procurações de juízes. Além disso, conforme relata o ministro, o restante da população brasileira mostrou simpatia a esses trabalhadores ou simples "falta de interesse", inviabilizando o sorteio (RMM, 1903). Assim, as principais formas de recrutamento da Marinha de guerra brasileira continuaram sendo o alistamento de voluntários, o recrutamento forçado e os egressos das escolas de aprendizes.

A despeito dessa combinação de fatores, o número insuficiente de praças da Marinha continuará uma constante até o final da década de 1900, como podemos ver no quadro 1. Importante observar que a Revolta da Armada de 1893 causou grandes perdas ao contingente de praças, com consequências para os anos seguintes. Da mesma forma, a chamada modernização técnica, com a substituição dos navios, também exigiu um aumento do número de efetivos desejados. Interessante concluir, enfim, que, às vésperas da revolta de 1910, o Corpo de Marinheiros Nacionais tinha aproximadamente $80 \%$ de seu total, o que indica que algo foi feito para remediar o problema da falta de braços. 
Quadro - Efetivos do Corpo de Marinheiros Nacionais (1888-1914)

\begin{tabular}{|c|c|c|c|c|}
\hline Ano & Efetivos & $\begin{array}{c}\text { Efetivos desejados } \\
\text { (Fixados para a } \\
\text { Força Naval) } \\
\end{array}$ & $\begin{array}{l}\text { Número de marinhei- } \\
\text { ros que faltam para } \\
\text { completar o corpo }\end{array}$ & $\begin{array}{c}\text { Percentagem } \\
\text { de preenchimento } \\
\text { do corpo }\end{array}$ \\
\hline 1888 & 3.218 & 3.300 & 82 & 98 \\
\hline 1889 & - & 4.000 & - & - \\
\hline 1890 & - & 4.000 & - & - \\
\hline 1891 & 2.951 & 4.012 & 1.054 & 74 \\
\hline 1892 & 3.174 & 4.012 & 838 & 79 \\
\hline 1893 & 916 & 4.012 & 3.096 & 23 \\
\hline 1894 & 1.248 & 4.012 & 2.764 & 31 \\
\hline 1895 & 1.789 & 4.000 & 2.292 & 43 \\
\hline 1896 & 1.809 & 4.000 & 2.191 & 45 \\
\hline 1897 & 1.792 & 4.000 & 2.208 & 45 \\
\hline 1898 & 1.904 & 4.000 & 2.096 & 48 \\
\hline 1899 & 1.981 & 4.000 & 2.019 & 50 \\
\hline 1900 & 1.946 & 4.000 & 2.054 & 49 \\
\hline 1901 & 2.091 & 4.000 & 1.909 & 52 \\
\hline 1902 & 2.552 & 4.000 & 1.448 & 64 \\
\hline 1903 & 3.014 & 4.000 & 986 & 75 \\
\hline 1904 & 2.661 & 4.000 & 1.339 & 67 \\
\hline 1905 & 2.760 & 4.000 & 1.240 & 69 \\
\hline 1906 & 2.866 & 4.000 & 1.134 & 72 \\
\hline 1907 & 3.120 & 4.000 & 880 & 78 \\
\hline 1908 & 3.274 & 5.000 & 1.726 & 66 \\
\hline 1909 & 4.097 & 5.000 & 903 & 82 \\
\hline 1910 & - & - & - & - \\
\hline 1911 & 2.335 & 5.000 & 2.665 & 47 \\
\hline 1912 & 4.032 & 5.000 & 968 & 81 \\
\hline 1913 & 4.449 & 6.000 & 1.968 & 74 \\
\hline 1914 & 4.700 & 5.000 & 300 & 94 \\
\hline
\end{tabular}

Fonte: RMM, 1888-1914

A carência de homens que marcou os primeiros anos da República associava-se também a uma lógica viciosa no interior da Marinha: se o tempo de ser- 
viço obrigatório era longo - que podia chegar a 15 anos para os aprendizes, dez para os voluntários, cinco para os reengajados e três para os sorteados - ele não podia ser reduzido, segundo alguns oficiais, justamente pela falta de braços. Além disso, os ex-alunos das escolas de aprendizes deviam permanecer durante mais tempo que os outros, a fim de "devolver" ao Estado o investimento dispensado para sua formação. Os oficiais reclamavam em vão dos baixos salários e das recompensas raramente concedidas às famílias dos aprendizes, o que afastava ainda mais os possíveis voluntários e esvaziava os navios.

A chegada da República não trouxe mudanças estruturais significativas a esse sistema. As companhias de aprendizes passaram a se chamar "escolas de aprendizes", os marujos passaram a pertencer ao Corpo de Marinheiros Nacionais, mas a legislação permanecia praticamente a mesma nos primeiros anos da República. Os castigos corporais continuavam sendo aplicados com base na lei, que previa o máximo de 25 chibatadas por dia, mas na prática esse número era ultrapassado em muito, chegando com frequência a 100, 200 ou 300 golpes dados diante de toda a tripulação (Nascimento, 2002; 2008). Além disso, o ofício de marinheiro continuava não atraindo muitos trabalhadores voluntários, como nos diz o ministro Custódio José de Melo em seu relatório de 1891:

O voluntariado sem prêmio nada nos pode prometer, visto que, com o desenvolvimento que ultimamente hão tido as nossas indústrias, tornou-se fácil e bem remunerado o trabalho, e ninguém deixará de nelas empregar-se para engajar-se como marinheiro com o mesquinho soldo de $9 \$ 375$ mensais. Esta quantia pode qualquer trabalhador ganhar em dois dias. (RMM, 1891:28).

Muitos dos voluntários alistados eram, de fato, coagidos pelas autoridades policiais, sobretudo a partir das brechas abertas pelo Código Penal da República de 1890, que punia, nos artigos 399 a 404, a "vagabundagem", a "capoeiragem" e a "mendicância". Segundo os termos da lei, a pessoa em uma dessas situações poderia ficar detida por alguns dias e se engajava a encontrar uma ocupação, que podia ser o enquadramento militar. Uma análise das fichas de identificação do Gabinete de Identificação da Marinha (GIM) - criado em 1908 justamente com a finalidade de "fichar" os praças e inibir as deserções - indica que alguns dos marinheiros nacionais e soldados navais eram conhecidos da polícia pelas contravenções citadas acima, mas eram minoritários (Almeida, 2009). No entanto, é preciso observar que essas interfaces entre a polícia e o recrutamento forçado - ou o voluntariado forçado - contribuíram bastante para a criação de um 
imaginário de "classes perigosas" associado aos praças da Marinha de Guerra e aos aprendizes marinheiros. Essa imagem é reproduzida no discurso do embaixador francês no Brasil, que escreve a seu ministro a propósito dos rebeldes de 1910:

As tripulações, na sua grande maioria compostas de negros e mulatos, provêm das escolas de "aprendizes marinheiros", jovens vagabundos e malfeitores, recolhidos pela polícia, ou jovens incorrigíveis, cujas famílias, em derradeiro ato de desespero, enviam a essas escolas como a uma casa de correção. 7

A solução para estabelecer um pessoal mais compatível com a modernização almejada foi reforçar a contratação de marujos através das escolas de aprendizes espalhadas pelo país, que já eram o "principal viveiro da Marinha de guerra" (RMM, 1906) desde 1855, contribuindo com aproximadamente $2 / 3$ dos incorporados como marinheiros nacionais em muitos períodos. Essas escolas passaram a receber uma crescente atenção das autoridades navais e tornaram-se parte integrante do debate sobre o futuro do Corpo de Marinheiros Nacionais. Contudo, eram alvo de críticas frequentes, consideradas casas de correção onde o ensino profissional e primário estava longe de ser uma prioridade. Ademais, a forma de concebê-las não era uma unanimidade. Dois modelos conviviam: um sugeria a diminuição do número de escolas para um melhor uso dos recursos, ao passo que o outro apostava na existência de várias escolas espalhadas pelo país. No período do ministro Alexandrino, o segundo modelo sairá vitorioso.

A justificação da necessidade dessas escolas não se restringia ao quadro interno da Marinha. De acordo com essa concepção, elas também exerceriam uma "função social": a de fornecer aos jovens delinquentes e sem família uma escolaridade e uma profissão. Para responder a um "antigo preconceito" e promover as realizações do ministério de Alexandrino de Alencar, o livro Nossa Marinha foi editado pela Imprensa Naval em 1910. Algumas passagens dessa obra propagandística explicam essa dupla importância das escolas de aprendizes e a visão da nova gestão do ministério:

Deste modo o nível do preparo das equipagens vem subindo sempre, ao passo que - fato digno de nota - a criminalidade baixa a um coeficiente até então não conseguido nos efetivos militares do país (...). Noutros tempos, havia o preconceito de que o serviço do mar era um castigo. Nada mais absurdo (...). O verdadeiro, o maior, o mais triste casti- 
go é o que inconscientemente nossas autoridades infligem à infância com o analfabetismo e a vadiagem, que no geral a embrutecem e infelicitam em muitas cidades da nossa terra. Ao contrário, o aluno de uma Escola de Aprendizes ali recebe a preparação intelectual, física, moral e profissional, que o dignifica, o aperfeiçoa e o salva (Dias, 1910: 264-266).

De fato, segundo o projeto de Alexandrino, o número de escolas chegava

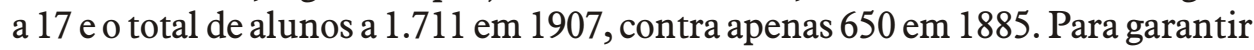
a formação e o máximo de braços à Marinha, as escolas se espalhavam pelos estados do Pará, Amazonas, Maranhão, Ceará, Rio Grande do Norte, Paraíba, Pernambuco, Alagoas, Sergipe, Bahia, Espírito Santo, Rio de Janeiro, São Paulo, Paraná, Santa Catarina e Rio Grande do Sul. Ainda que bastante concentradas no litoral do país, essa dispersão geográfica das escolas exercia igualmente uma dupla função ou "interesses recíprocos". Segundo o ministro Júlio César de Noronha (RMM, 1903:58), elas deviam atrair jovens de outras regiões e nutrir os estados de instituições que os proviam tanto de um lugar para enviar suas crianças "desvalidas", quanto de formas para "consumir seus respectivos produtos locais". Consequentemente, mas também devido ao deslocamento interno da população brasileira no período, $84,8 \%$ dos praças da Marinha, a partir de uma análise de uma amostra de indivíduos identificados pelo Gabinete de Identificação em 1908, não eram originários da capital federal ou do Estado do Rio e 65,6\% vinham do Norte ou do Nordeste (Almeida, 2009).

Para além desse esforço material, como era de fato o cotidiano dessas instituições e quais as expectativas de seu público, os futuros praças da Marinha? Muitos são os relatos que atestam o baixo nível de alfabetização dos aprendizes, prematuramente transferidos para os navios da Armada em constante demanda de pessoal (Macedo Soares, 1911:84). A análise de outros documentos, porém, pode nos indicar pistas diferentes. Entre os exageros do discurso ufanista e as imagens negativas que tinham essas instituições, podemos perceber algumas nuances e particularidades envolvendo o projeto de modernização do pessoal. A publicação oficial da Marinha elogiava também os resultados obtidos pela gestão de Alexandrino, como nos indica a passagem seguinte:

O resultado desta orientação é desde já magnífico. Basta averbar que no ano de 1908 esses viveiros forneceram à armada cerca de 700 grumetes, e em 1909 nada menos de 905, todos sabendo ler e escrever, familiarizados com a vida de bordo e adestrados nalguma das especialidades da Marinha moderna: sinaleiros, timoneiros, torpedistas, artilheiros... (Dias, 1910:232) (grifo nosso). 
Muito provavelmente, esse discurso é exagerado, mas é interessante observar como, através dos termos utilizados, revela-se uma forma de pensar: as escolas são novamente consideradas como "viveiros" onde os aprendizes seriam "adestrados". A utilização de palavras próprias ao universo animal mostra que um dos objetivos evidentes das escolas era também o de civilizar esses jovens oriundos das classes populares, negros, mestiços, provincianos, nortistas e nordestinos.

As imagens dessas instituições produzidas por fotógrafos oficiais da Marinha também vão no mesmo sentido. Em Nossa Marinha, três representações mostram a organização da Escola de Aprendizes do Rio de Janeiro em locais diferentes: no refeitório, na sala de aula e no dormitório (imagem 1). Nos três casos, os ambientes são impecáveis e tem-se a impressão, através da "dimensão realística" da fotografia (Barthes, 1995:1165), de tratar-se realmente de um grande esforço material e humano de parte das autoridades navais, num momento em que a educação pública estava longe de ser massiva e em que o número de órfãos e abandonados era bastante importante, como demonstram outros trabalhos (Priori, 2006). Ao lado de estabelecimentos como a Igreja e os orfanatos, as instituições militares também tinham a intenção de prestar um serviço à infância sem futuro, como atestam a imagem que pretendiam passar.

\section{Imagem 1 - Dormitório da escola de aprendizes marinheiros do Rio de Janeiro}

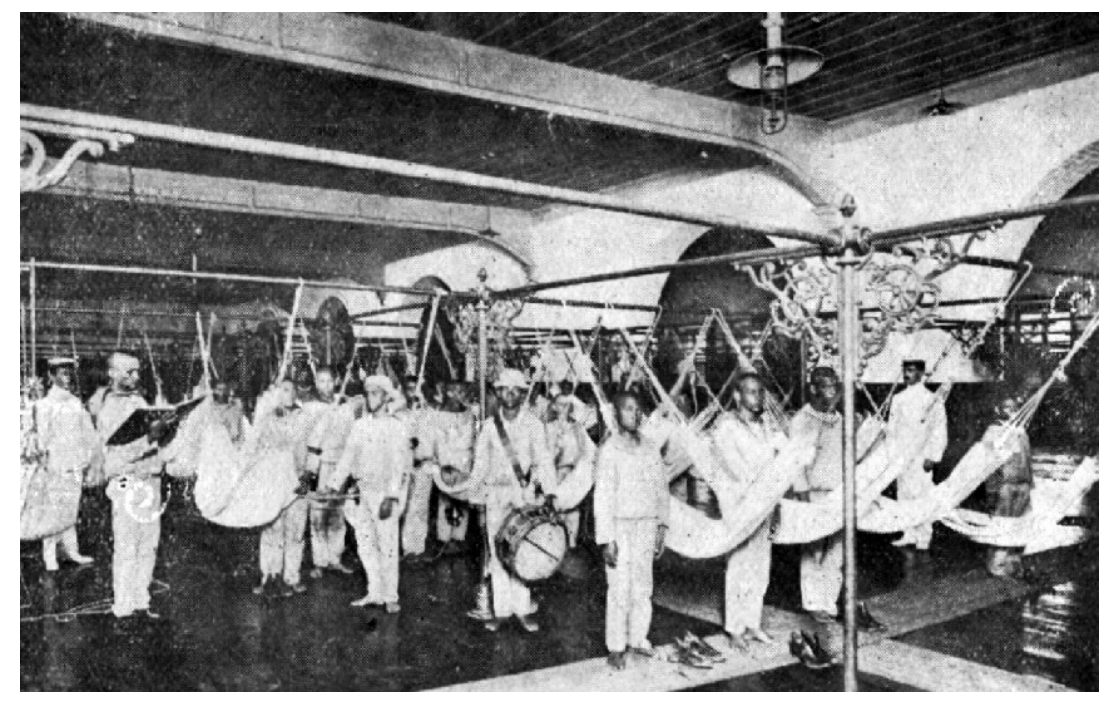

Fonte: Dias, 1910. 
Os regulamentos das escolas de aprendizes relativos aos anos de 1885 e de 1907 indicam poucas mudanças entre eles. Em ambos os casos, os aprendizes deviam cursar três anos e não podiam se desengajar por outro motivo senão a incapacidade física ou mental. Só seriam transferidos ao Corpo de Marinheiros Nacionais aos 18 anos, salvo se tivessem mau comportamento, já demonstrassem ter capacidade física suficiente (regulamento de 1885) ou se mostrassem inaptos ao estudo (regulamento de 1907). Existia uma série de punições para manter a disciplina, até mesmo os castigos corporais. Os domingos eram considerados dias de repouso, mas o aprendiz só poderia sair fardado da escola.

Algumas mudanças quanto às disciplinas ensinadas se faziam, no entanto, presentes. No regulamento de 1907, a doutrina cristã desaparece das exigências e a carga do ensino de aritmética e de língua portuguesa é reforçada. A maior mudança diz respeito à introdução do ensino profissional através de oficinas, como a carpintaria. As atividades físicas ganham também maior espaço, como a ginástica, a natação e até mesmo o futebol. Os cursos seriam ministrados majoritariamente por militares, e não por professores primários, que só são contratados em maior número a partir da década de 1910, segundo dados relativos à escola do Ceará (Aquino, 2000).

É preciso desconfiar da aplicação desses regulamentos, pois diversos testemunhos e experiências nos mostram que entre a legislação e a prática havia sempre uma grande diferença (Nascimento, 2001, 2008). Mas eles nos dizem bastante sobre os modelos pensados. Quanto aos resultados dos alunos, a análise da documentação referente à Escola de Aprendizes de Salvador nos revela ainda outros elementos ${ }^{8}$. Mesmo tratando-se de um período anterior - anos 1860 -, algumas notas indicam que os alunos eram avaliados com relação ao conhecimento de gramática, catecismo, operações básicas, tabuada, geografia e história do Brasil. Outras anotações indicam que alguns alunos já escreviam "bastardo" ou seja, em letras primárias antes do domínio da caligrafia - em letras "finas" ou cursivas ou já "davam Bom Homem Ricardo". Bom Homem Ricardo era a cartilha adotada por diversas instituições de ensino da época e consistia na tradução de máximas de Benjamin Franklin com conselhos sobre como enriquecer. Esse manual não era adotado por acaso na formação de praças da Marinha: os textos curtos combatiam a ociosidade e a perda de tempo, indicando o caminho do trabalho em contraposição à vagabundagem, ao alcoolismo, ao jogo e ao desperdício com coisas mundanas (Almeida, 2009).

Assim, o objetivo curricular dessas escolas compreendia algo mais do que a formação primária ou técnica do marujo. Tratava-se de um verdadeiro projeto de ensino de boa conduta moral, em que a higiene também se fazia pre- 
sente. Alguns anos mais tarde, mas ainda nesse mesmo contexto, o Manual do aprendiz marinheiro da escola do Ceará sintetiza os conteúdos que deviam ser ensinados nas escolas. Sua primeira recomendação aos marinheiros diz o seguinte: "Sejam limpos porque a falta de asseio é repugnante e produz moléstias". A segunda afirma o seguinte: "Evitem o álcool e o jogo: o álcool arruína a saúde e o jogo perverte o caráter." (1922: 6). Disciplina, higiene e obediência pesavam bem mais do que a formação em outros sentidos, já que "o tipo ideal de um marinheiro é o de um homem vivo, asseado, correto, desembaraçado, sempre pronto a cumprir com satisfação as ordens." (1922: 5). Uma fotografia da mesma instituição, datada de 1917, representa esse ideal-tipo de marinheiro, limpo e uniformizado. A representação do momento do corte de cabelo indica exatamente essa passagem que as autoridades da Marinha desejavam que o indivíduo fizesse para integrar suas escolas e posteriormente o Corpo de Marinheiros Nacionais.

\section{Imagem 2: Escola de aprendizes do Ceará (1917)}

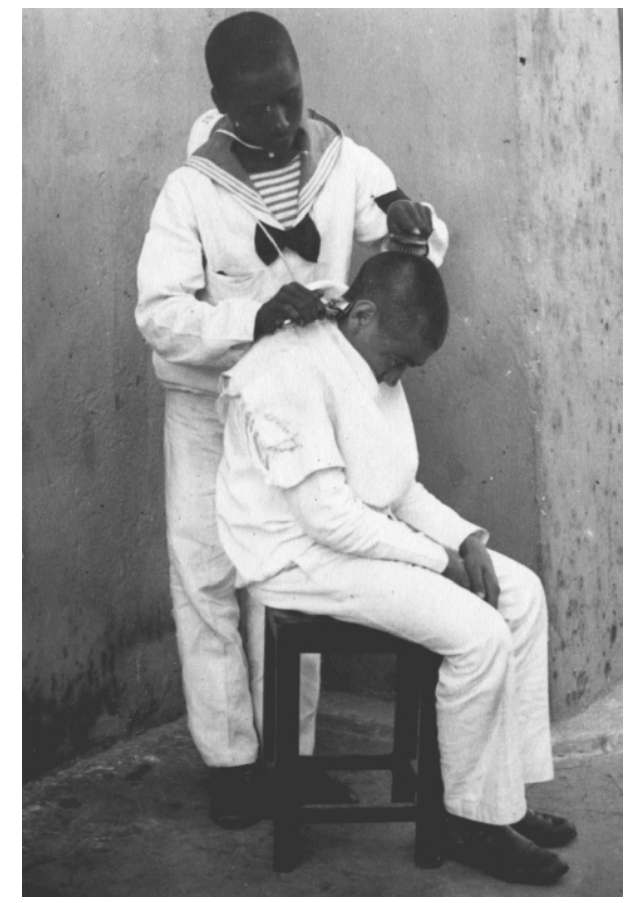

Fonte: SDM, Divisão de Documentos Especiais, Fundo: imagens, Série: Escola de Aprendizes: Escola do Ceará, 1917. 


\section{Quando o pessoal encontra o material: trajetórias dos marujos de 1910}

No contexto do final do Império e primeiros anos da República, algumas trajetórias e experiências revelam-nos ainda que essas escolas podiam atender a certas expectativas dos alunos, pais e tutores. O marinheiro Adalberto Ferreira Ribas, um dos líderes da Revolta de 1910, escolheu inscrever-se aos 14 anos como aprendiz na escola de Salvador para fugir ao seminário e à educação rígida, aplicada por padres franceses e italianos, a quem fora confiado pela mãe, segundo contou a seus filhos (Almeida, 2009). Sua caderneta subsidiária indica que foi alistado em seguida na Marinha de Guerra como grumete em 1908, aos 15 anos. Tinha nível escolar bastante bom, tornando-se professor após fugir à repressão das autoridades aos rebeldes. É provável, porém, que sua instrução se devesse bem mais ao seminário do que à escola de aprendizes.

Para outro marinheiro indiciado pelo processo de 1912 (que visava avaliar a participação dos rebeldes de novembro de 1910 na revolta do Batalhão Naval em dezembro do mesmo ano), a passagem pela escola de aprendizes também parecia ser uma escolha. Conforme indica uma carta apreendida da mãe de Miníbio Pereira da Silva dirigida ao filho:

Querido Miníbio, é com meu coração bem triste (...) que lanço a mão a pena para que te encontre melhor, filho. (...) Esses teus amigos traidores. Tu não recordas, Miníbio, o quanto sofreste nessa escola por causa dos maiores ... foste embora e andaste na Europa, foste tão feliz (...) foste limpo na tua caderneta. Como é que viraste o pensamento e seguiste o caminho que teus amigos seguiram?

As escolas davam a oportunidade de conhecer outros países e ter uma carreira, muito embora fosse preciso ter cuidado com as "más influências", segundo o olhar dessa mãe. Esse extrato permite pensar, junto com outros trabalhos, que nem sempre os pais e tutores eram atraídos para essas escolas em razão dos prêmios financeiros. Eles podiam também ser movidos pela busca de melhores condições num contexto em que havia raríssimas alternativas de aprendizagem profissional destinadas à infância carente, como também demonstrou Renato Pinto Vênancio (2006: 199). No entanto, podemos pensar que, para Miníbio e outros, essa diferença entre "bons" e "maus" podia não ter o mesmo significado que tinham para as autoridades e até para os pais de marujos, já que os dois grupos andavam juntos na organização do movimento de $1910 .{ }^{10}$

O líder dos rebeldes de 1910, o marinheiro negro primeira-classe João Cândido, também passou por uma escola de aprendizes. Nascido em 1880 em 
Rio Pardo, no Rio Grande do Sul, e filho de escravos, foi levado pelas mãos do próprio almirante Alexandrino de Alencar, que conhecia sua família, a alistar-se na escola desse estado aos 14 anos, em 1884 (Morel, 2009). Embora não saibamos ao certo as razões que levaram a esse alistamento, quase um ano depois João Cândido foi incorporado como grumete no quartel de Villegagnon, no Rio de Janeiro. Embora o regulamento previsse o alistamento a partir dos 18 anos, este e muitos outros casos indicam que os meninos eram enviados antes para servir nos navios de guerra. Entre a escola de aprendizes do Rio Grande do Sul e os navios, ele aprendeu a ler, escrever, contar, bordar e a operar diversas técnicas de navegação.

Mesmo tendo liderado a maior revolta de praças da Marinha da história brasileira, João Cândido nunca almejou deixar a instituição naval, como indicam seus testemunhos. Seu desejo era transformá-la (Morel, 2009; MIS, 1999). Se ele guardou poucas lembranças de sua vida como aprendiz, soube reconhecer o papel da Marinha na sua instrução: "Entrei na Marinha com 14 anos e entrei bisonho. (...) Toda a luz que me iluminou, que me ilumina, graças a Deus, que é pouca, foi adquirida, posso dizer, na Marinha" (MIS, 1999: 87).

Além desses exemplos, muitos outros participantes da revolta de 1910 passaram por essas escolas. Junto com a mudança de regime e os investimentos no material, as escolas e os esforços para alterar o sistema de recrutamento podem ter contribuído para a formação do crescimento do espírito de corpo entre os marinheiros, que se viam provavelmente unidos na identidade de marinheiros nacionais. Se Alexandrino foi um dos maiores "mentores" de um dos projetos, entre outros, de modernização institucional da Marinha, tanto pessoal quanto material, João Cândido, seu protegido, foi o principal líder de uma revolta de marujos que pedia melhores condições de tratamento e de trabalho, bem como de instrução "para os marinheiros que não têm competência para vestir a orgulhosa farda". Eles se reconheciam e se revindicavam como "nós, marinheiros, cidadãos brasileiros e republicanos", em seu manifesto de novembro de 1910 (Morel, 2009: 97).

Pensadas como verdadeiras instituições de moralização das crianças e de recuperação da infância carente, as escolas de aprendizes marinheiros foram a saída proposta para modernizar o recrutamento. Podiam ser vistas como alternativas para as classes populares, mas também como ineficientes e como antros de concentração de vagabundos e delinquentes. Quanto às encomendas de navios, faziam parte de um projeto elogiado e aplaudido por diversas categorias da sociedade, mas também revelava as dificuldades de afirmação da jovem República brasileira no quadro internacional.

Nesse sentido, sob a couraça dos dreadnoughts, havia muitos problemas e tão logo os navios foram lançados ao mar, já eram representados pela caricatura como "elefantes brancos" (O Malho, 03/12/1910). A discussão aqui apresentada propõe entender a "modernização" da Marinha republicana como mais comple- 
xa e diferente do que pretenderam algumas correntes da historiografia até hoje e pensar como, muitas vezes, as classes populares também podem se inserir, à sua maneira, nos planos de "modernização". Projetos para modernizar o material e o pessoal da Marinha existiram e eles estavam cheios de contradições.

\section{Notas}

1. Esta revolta é conhecida pela historiografia como "Revolta da Chibata", título do livro do jornalista Edmar Morel publicado pela primeira vez em 1959 (Morel, 2009).

2. $\mathrm{O}$ argumento da contradição entre a dimensão material e pessoal é retomado por diversos autores, como Maestri (2000) e Morgan (2001), ainda que, como foi dito, seus discursos sejam bastante diferentes do pensamento do "oficial da marinha" Macedo Soares.

3. Esses relatórios encontram-se disponíveis em: http://www.crl.edu/brazil/ ministerial

4. Archives du Quai d'Orsay, Correspondance politique et commerciale, Défense Nationale, vol. 3, 24/09/1908 (tradução nossa).

5. Idem, 09/05/1909.

6. Idem, 03/06/1909.

\section{Referências bibliográficas}

ALENCAR, Carlos Ramos de. Alexandrino, o grande marinheiro. Rio de Janeiro: Serviço de Documentação Geral da Marinha, 1989.
7. Archives du Quai d'Orsay, Correspondance politique et commerciale, Politique Intérieure - Immigration, vol. 6, 28/11/1910.

8. AN, Série Marinha, Fundo AP, Livro de Matriculados Menores da $2^{\mathrm{a}}$. Cia de Aprendizes do Arsenal de Marinha da Bahia tendo principiado a funcionar o ensino primário em 8 de setembro de 1860 , Cia. De Artífices - matrícula de menores, 1860, VIII M-92.

9. AN, Supremo Tribunal Militar, Processo "João Cândido e outros", Série Judiciária, Subsérie: Processo Crime; 1913, BW 2847, v. 1, f. 18.

10. A análise dos históricos de alguns praças que participaram da revolta revela também que, na maior parte dos casos, eles oscilavam entre períodos de bom e mau comportamento, o que nos impossibilita, mais uma vez, de dividi-los entre grupos de "bons" e "maus" (Almeida, 2009).

ALMEIDA, Sílvia Capanema P. de. "Nous, marins, citoyens brésiliens et républicains": identités, modernité et mémoire de la révolte des matelots de 1910. Tese (Doutorado em 
História), École des Hautes Études en Sciences Sociales, Paris, França, 2009.

ALMEIDA, Sílvia Capanema P. de. Être noir, brésilien et marin. Identités et citoynneté dans la période post-abolitionniste (1888-1914). In: ALMEIDA, Sílvia Capanema P. de \& FLECHET, Anaiis (org). De la démocratie raciale au multiculturalisme: Brésil, Amériques, Europe. Bruxelas: Peter Langue, 2009, p. 53-74.

AQUINO, Dolores. Escola de aprendizesmarinheiros do Ceará. Resgate histórico: criação e evolução. Fortaleza: Gráfica e Editora Tipografia Progresso, 2000.

ARENDT, Hannah. Condition de l'homme moderne. Paris: Calmann-Lévy, 1983.

ARIAS NETO, José Miguel. Em busca da cidadania: praças da Armada nacional, 18671910. Tese (Doutorado em História), Universidade de São Paulo, São Paulo, Brasil, 2001.

BARTHES, Roland. La Chambre claire. In: BARTHES, Roland. Euvres complètes, t. III, Paris: Seuil, 1995.

BEATTIE, Peter. The Tribute of Blood: Army, Race and Nation in Brazil, 1864-1945. Durham: Duke University Press, 2001.

BUENO, Clodoaldo. Política externa da Primeira República: os anos de apogeu - de 1902 a 1918. São Paulo: Paz e Terra, 2003.

CASTRO, Celso; IZECKSOHN, Vitor \& KRAAY, Hendrik (orgs.). Nova história militar brasileira. Rio de Janeiro: FGV, 2004.

DIAS, Arthur. Nossa Marinha: notas sobre o renascimento da Marinha de guerra do Brazil no quatriennio de 1906 a 1910. Rio de Janeiro: Officinas Graphicas da Liga Maritima Brazileira, 1910.

DUMONT, Louis. Essais sur l'individualisme: une perspective anthropologique sur l'idéologie moderne. Paris: Seuil, 1983.
ESCOLA de Aprendizes do Ceará. Manual do aprendiz marinheiro. Fortaleza: Typ. Gadelha, 1922.

FREYRE, Gilberto. Ordem e progresso. Rio de Janeiro: Record, 2000 (5a ed.) [1959].

HEINSFELD, Adelar. Estanislau Severo Zeballos: artífice da política armamentista argentina no início do século XX. Comunicação apresentada na $26^{e}$. Reunião da Sociedade Brasileira de Pesquisa Histórica, julho 2006.

LE GOFF, Jacques. Histoire et mémoire. Paris: Gallimard, 1988.

MACEDO SOARES, José Eduardo [Um oficial da Marinha]. Política versus Marinha, Paris, 1911.

MAESTRI, Mário. Cisnes negros: uma história da Revolta da Chibata. São Paulo, Moderna, 2000.

MARTINS FILHO, João Roberto. $A M a$ rinha brasileira na era dos encouraçados, 18951910. Rio de Janeiro: FGV, 2010.

MARTINS, Hélio Leôncio. A revolta dos marinheiros, 1910. São Paulo: Editora Nacional; Rio de Janeiro: Serviço de Documentação Geral da Marinha, 1988.

MUSEU DE IMAGEM E DO SOM. Foão Cândido, o almirante negro, Rio de Janeiro: Gryphus, Museu da Imagem e do Som, 1999.

MOREL, Edmar. A revolta da chibata [organização de Marco Morel]. $5^{\mathrm{a}}$ ed. Rio de Janeiro: Paz e Terra, [1958], 2009.

MORGAN, Zachary Ross. Legacy of the Lash: Black and Corporal Punishment in the Brazilian Navy, 1860-1910. Tese (Doutorado em Filosofia) - Departamento de História, Brown University, Providence, Estados Unidos, 2001.

NASCIMENTO, Álvaro Pereira do. $A$ ressaca da marujada : recrutamento e disciplina na Armada imperial. Rio de Janeiro: Arquivo Nacional, 2001. 
- Cidadania, cor e disciplina na revolta dos marinheiros de 1910. Rio de Janeiro: Mauad/Faperj, 2008.

VENÂNCIO, Renato Pinto. Os aprendizes da guerra. In: PRIORE, Mary del (org.).
História das crianças no Brasil. São Paulo: Contexto, 2006, p. 192-209.

VERGE-FRANCESCHI, Michel. Dictionnaire d'histoire maritime. Paris: Éditions Robert Laffont, 2002.

\title{
Resumo
}

O artigo discute o processo de "modernização" da Marinha brasileira no fim do Império e início da Primeira República a partir dos projetos desenvolvidos para a sua dimensão material (equipamentos) e pessoal (recrutamento e formação militar), destacando-se o papel do ministério de Alexandrino de Alencar (1906-1910). Critica-se uma abordagem tradicional da historiografia que sustenta a existência de um abismo entre essas duas dimensões e colocam-se em evidência as contradições existentes no interior desses dois universos. A argumentação demonstra como havia, em torno dos projetos navais, um jogo de interesses e de limitações relativas ao lugar que a República brasileira ocupava no período e como as soluções pensadas para resolver o problema do recrutamento e da falta de pessoal passavam pelos modelos de escolas de aprendizes marinheiros. Mesmo se havia uma busca de "civilizar" os indivíduos que se tornariam futuros marujos, esses esforços materiais e humanos foram sentidos e vividos à sua maneira pelos praças, reforçando a identidade comum e criando bases para a revolta de 1910, acontecimento que se insere no processo de modernização da Armada nacional.

Palavras-chave: Marinha brasileira, modernização, material, recrutamento, escolas de aprendizes

\begin{abstract}
This article discusses the process of "modernization" in the Brazilian Navy in the late Empire and in the beginning of the First Republic. It concerns the plans and projects developed for both naval materiel (ships) and personnel (recruitment and military organization), focusing on the ministry of Alexandrino de Alencar (1906-1910). We criticize a traditional historical approach, which stresses the existence of a gap between the modern equipment and the backward methods of recruiting and training the men. Instead, we propose to discuss the contradictions existing within those universes (personnel and materiel). Our argument demonstrates how the
\end{abstract}


naval bills in congress were impacted by many special interest groups and by the limits of the Brazilian Republic in the period. We also demonstrate that the solutions envisaged for resolving the enlistment and understaffing problems were focussed on the school of naval apprentices. Although the goal was to "civilize" future sailors, government actions were felt and interpreted by the seamen in their own way, contributing to a strong sense of common identity. Such efforts also set the stage for the 1910 mutiny, which itself became part of the Brazilian Navy's modernization process.

Keywords: Brazilian navy, modernization, equipment, enlistment, naval school of apprentices

\section{Résumé}

Cet article analyse le processus de « modernisation » de la Marine de guerre brésilienne à la fin de l'Empire et au début de la Première République à partir des projets de rénovation matérielle (équipements) et humaine (formation et recrutement des militaires), mis en œuvre notamment pendant le ministère Alexandrino de Alencar (1906-1910). L'étude remet en question la division traditionnellement admise par l'historiographie entre le personnel et le matériel et montre que des contradictions existaient à l'intérieur de chacune de ces dimensions. D'une part, elle met à jour les intérêts en jeu et les limites des projets navals brésiliens, dans le contexte national et international du tournant des XIXe et XXe siècles. D'autre part, elle montre que les solutions envisagées pour résoudre le problème du sous-effectif contribuèrent à remodeler les écoles d'apprentis-marins. Si l'ensemble de ces projets étaient portés par le désir de «civiliser » les futurs marins de la République, ils ont également été ressentis et vécus à leur manière par les matelots. Ils ont notamment contribué à créer une identité commune, créant les bases pour la révolte de 1910, un événement qui s'inscrit lui-aussi dans le cadre de la modernisation de l'Armada brésilienne.

Mots-clés: Marine brésilienne, modernisation, équipements, recrutement, écoles d'apprentis-marins. 